\title{
GERENCIAMENTO DE RECEITA (RM) E BUSINESS ANALYTICS (BA) COMO UM RECURSO ESTRATÉGICO ORGANIZACIONAL
}

\author{
REVENUE MANAGEMENT (RM) AND BUSINESS ANALYTICS (BA) AS A \\ STRATEGIC ORGANIZATIONAL RESOURCE
}

\author{
Claudia Cavalcanti \\ Universidade Estácio de Sá - RJ \\ claudiaxc.andrade@terra.com.br
}

Submissão:02/12/2020

Aprovação: $31 / 05 / 2021$

\begin{abstract}
RESUMO
Objetivo deste artigo é compreender Business Analytics como um recurso estratégico no contexto do Gerenciamento de Receita em uma companhia aérea. Nesse âmbito, para responder à questão central desta pesquisa optou-se pela condução de uma pesquisa qualitativa. O processo de coleta de dados foi realizado por meio de observação direta (não participante), de entrevistas e de análise documental. Para a análise de dados, foi realizada uma análise de conteúdo pelo método de análise em espiral de Creswell (2013). Foi possível avançar na abordagem da Visão Baseada em Recursos ao fazer uma articulação teórica entre o campo de Business Analytics (BA) e Gerenciamento de Receita (RM). Ao descrever a rotina na área de Gerenciamento de Receita, foi possível identificar, dentro do modelo VRIO (BARNEY, 1995), como cada atributo foi evidenciado ao buscar garantir a eficiência e eficácia dos recursos que são utilizados pela organização. Os resultados apontaram que os recursos analíticos (humanos, físicos e organizacionais) se mostraram presentes nos atributos VRIO de forma diferenciada, sendo que os únicos recursos que estiveram presentes nos quatro atributos foram os organizacionais, apontando vantagem competitiva de longo prazo nesse quesito.
\end{abstract}

Palavras-Chave: Business Analytics, Visão baseada em Recursos, Gerenciamento de Receita, VRIO, Companhia Aérea.

\begin{abstract}
The purpose of this article is to understand how Business Analytics is identified as a strategic resource in the context of Revenue Management in an airline. In this context, to answer the central question of this research, it was decided to conduct a qualitative research. The data collection process was carried out through direct observation (non-participant), interviews and document analysis. For data analysis, a content analysis was carried out using the spiral analysis method of Creswell (2013). It was possible to advance the approach of the Resource Based View by making a theoretical articulation between the field of Business Analytics (BA) and Revenue Management (RM). When describing the routine in a Revenue Management area, it was possible to identify, within the VRIO model (BARNEY, 1995), how each attribute was evidenced when trying to guarantee the efficiency and effectiveness of the
\end{abstract}


resources that are used by the organization. The results showed that the analytical resources (human, physical and organizational) were shown to be present in the VRIO attributes in a different way, and the only resources that were present in the four attributes were the organizational ones, pointing out long-term competitive advantage in this issue.

Keywords: Business Analytics, Resource Based View, Revenue Management, VRIO, Airline Company

\section{INTRODUÇÃO}

O processo de tomada de decisões tem sido uma prática inerente ao cotidiano das organizações e muitas vezes ele é apresentado como uma prática racional, na qual os indivíduos tomam decisões coletando, integrando e analisando dados. Dentro dessa perspectiva racional de processo decisório, em função dos avanços tecnológicos que têm emergido ultimamente, tem havido um debate a respeito da abordagem analítica, ou como é conhecida na linguagem mercadológica, Business Analytics (BA).

Business Analytics vem sendo definido como o uso extensivo de dados, de análise estatística e quantitativa, de modelos explicativos e preditivos e de gestão baseada em fatos e dados para impulsionar decisões (DAVENPORT; HARRIS, 2007; DAVENPORT, 2013). BA também é definida como uma abordagem holística para gerenciar, processar e analisar dados (ASHRAFI et al., 2018), não só para criar insights, mas também para permitir que as organizações possam prever mudanças com base nos requisitos do mercado e respondê-las rapidamente (ISIK; JONES; SIDOROVA, 2013).

No entanto, embora a teoria existente (KAHNEMAN, 2011) sugira que o uso de Analytics possa ser alinhado à tomada de decisões organizacionais, não está claro como isso pode ser alcançado (GROVER et al., 2018; KRISHNAMOORTHI; MATHEW, 2018), pois há uma escassez de pesquisa empírica para fundamentar essa proposição e orientação prática para gestores que procuram adotar Business Analytics. Este estudo argumenta, portanto, que uma organização pode melhorar seu processo decisório desenvolvendo sua capacidade de análise para capturar, integrar e analisar dados e informações e usar os insights obtidos com dados e informações no contexto da tomada de decisões organizacionais (TAN et al., 2016).

Para alcançar o propósito de um estudo sobre BA, foi necessário identificar alguns modelos organizacionais de tomada de decisão existentes que envolvem o uso da tecnologia e das pessoas de forma integrada, sendo uma delas a prática de gerenciar receitas. Segundo Strauss, Klein e Steinhardt (2018), Revenue Management (RM) refere-se à prática de gerenciamento de demanda suportada por TI, por meio de preços ou disponibilidade de produto com base em modelos de demanda, de modo a maximizar lucros ou receita. Portanto, utiliza modelos de Analytics nas análises operacionais.

O gerenciamento de receita ganhou atenção como uma área de aplicação relevante no campo da pesquisa operacional. A prática cresceu a partir de grandes companhias aéreas na era pósdesregulamentação nos Estados Unidos (em torno de 1978) e é utilizada até hoje como uma prática comercial convencional, como, por exemplo, na indústria do entretenimento (ex: Walt Disney), em companhias aéreas, cadeias hoteleiras e empresas de aluguel de carros. Essas empresas possuem funcionários atuando como desenvolvedores e analistas em RM, e as principais empresas de consultoria e software também empregam um grande número de profissionais para desenvolverem soluções de RM (TALLURI; RYZIN, 2004; GALLEGO; TOPALOGLU, 2019).

Nesse âmbito, esta pesquisa terá como campo de investigação a área de Gerenciamento de Receitas (Revenue Management) de uma Companhia Aérea brasileira localizada no estado de 
São Paulo, que por questões previstas no seu acordo de confidencialidade, terá seu nome preservado e aqui será chamada com o nome fictício de STAR. A escolha da Companhia aérea se deu pelo fato de Gerenciamento de Receita ser considerada uma área de aplicação de Analytics em companhias aéreas (CROSS,1997; TALLURI; RYZIN, 2004; SLACK; CHAMBERS; JOHNSTON, 2008; STRAUSS; KLEIN; STEINARDT, 2018; GALLEGO; TOPALOGLU, 2019), logo, como Analytics é a base de discussão desta pesquisa, estudar esse perfil de empresa se torna pertinente, inclusive pelo ineditismo da associação de BA com RM. A análise dessa relação promoverá, portanto, um avanço nos estudos sobre BA/RM.

A partir dessa escolha, esta pesquisa adotará a lente teórica da Visão Baseada em Recursos (VBR), que pode ser compreendida como uma perspectiva da estratégia que explica a vantagem competitiva a partir dos recursos e capabilidades da empresa (PENROSE, 1959; BARNEY, 1991). Baseando-se em pesquisas sustentadas pela VBR que sugerem que a capabilidade analítica provavelmente está relacionada com outras capabilidades / recursos organizacionais (AKTER et al. 2016; TAN et al. 2016; KRISHNAMOORTHI; MATHEW, 2018), este estudo postula que a capabilidade analítica de uma organização aprimora sua capacidade de detecção do ambiente, por meio do uso de ferramentas analíticas no âmbito de BA. A escolha da VBR como lente de análise se deve pelo fato de a pesquisa fornecer vários insights sobre a utilização dos recursos analíticos (BA) disponíveis pela organização em resposta à concorrência e consequentemente com o objetivo de se obter vantagem competitiva.

Portanto, o objetivo central desse artigo é compreender Business Analytics como um recurso estratégico no contexto do Gerenciamento de Receita em uma companhia aérea. Para responder à questão central desta pesquisa optou-se pela condução de uma pesquisa qualitativa. A justificativa para esta escolha é que esta abordagem permite a compreensão aprofundada do fenômeno no contexto em que ocorre, a partir da interação com o fenômeno em estudo, permitindo a observação, exploração e compreensão de aspectos relacionados às práticas (BOGDAN; BIKLEN, 1994).

Para cumprir essa finalidade, a presente pesquisa utilizou como instrumento de coleta de dados a técnica de observação não participante por meio de um diário de campo para registrar a dinâmica da área Gerenciamento de Receitas (RM) de uma Companhia Aérea. Também contempla análise documental, por meio da visualização de diversos relatórios gerenciais utilizados na área pesquisada e por 7 (sete) entrevistas semiestruturadas com profissionais da área de RM. Para a análise de dados, foi realizada uma análise de conteúdo pelo método de análise em espiral de Creswell (2013).

$O$ presente artigo se estrutura da seguinte maneira: além desta introdução, temos o referencial teórico dividido em 3 partes ("Visão Baseada em Recursos", "Business Analytics e VBR", "Revenue Management", em seguida a investigação e seu contexto, a análise dos dados, discussão dos resultados, conclusão e referências.

\section{REFERENCIAL TEÓRICO}

\subsection{VISÃO BASEADA EM RECURSOS}

De acordo com Miller (2019), a Visão Baseada em Recursos (VBR) é um conjunto de teorias relacionadas que compartilham as premissas de heterogeneidade e imobilidade de recursos entre as empresas. Nessa visão, uma empresa é um conjunto de recursos, capabilidades ou rotinas que geram valor e não podem ser facilmente imitados ou apropriados pelos concorrentes. A VBR compreende teorias que explicam a existência de vantagem competitiva (sustentada) e de rendas econômicas. A pesquisa empírica a partir desta perspectiva aborda o desempenho da empresa e o comportamento da empresa no nível da estratégia de negócios 
(por exemplo, competição dentro da indústria) e estratégia corporativa (por exemplo, aquisições) (MILLER, 2019).

A Visão Baseada em Recursos (VBR) foi inicialmente desenvolvida por meio de uma série de artigos de vários autores nas décadas de 1980-1990 (WERNERFELT, 1984; GRANT, 1991; BARNEY, 1991; 1995). Nesse sentido, os recursos da firma incluem todos os ativos, capabilidades, processos organizacionais, atributos, informação, conhecimento, etc, controladas por uma firma de forma que possibilite que ela implemente estratégias que melhorem sua eficiência e eficácia (BARNEY, 1991). Capabilidade neste artigo é entendida como a qualidade de ser capaz, ou seja, atributos de uma firma que a possibilitam explorar seus recursos na implementação de suas estratégias (BARNEY; CLARK, 2007). Em suma, a teoria da visão baseada em recursos surgiu com o objetivo de desenvolver ferramentas para analisar a posição da empresa em relação aos recursos por ela utilizados e, a partir dessa análise, propor opções de estratégias a serem seguidas pela empresa (WERNEFELT, 1984).

Barney (1991) aborda que para uma empresa possuir vantagem competitiva sustentável, é necessário que os recursos da empresa possuam quatro atributos: Seja valioso (V), no sentido em que explora oportunidades e/ou neutraliza ameaças no ambiente da firma; Deve ser raro (R) entre as empresas atuantes no mercado e os seus potenciais concorrentes; Não deve ser perfeitamente imitável (I); Ser imperfeitamente substituível (N). O primeiro modelo de Barney (1991) pode ser chamado tanto de VRIN ou VRIS (Valioso, Raro, Imitabilidade e Substituibilidade). Posteriormente, Barney (1995) faz uma pequena alteração no seu Framework VRIS/VRIN. Os três primeiros atributos foram mantidos, porém o último, a substituibilidade $(\mathrm{S})$ foi trocado por organização $(\mathrm{O})$, tornando o modelo conhecido como VRIO. O atributo "Organização" se deve ao fato de que apesar de a empresa possuir recursos e capacidades valiosos, raros e de difícil imitabilidade, para garantir o potencial de geração de vantagem competitiva desses recursos, a empresa deve estar devidamente organizada de forma a explorá-los. A exclusão do atributo "substituibilidade" foi devido ao fato de que ele de uma certa forma está embutido no atributo "Imitabilidade".

Desde sua introdução por Barney (1995), a estrutura VRIO (Valuable, Rare, Inimitable, Organizational) tornou-se um teste padrão de quão bem uma competência central específica fornece ou não vantagem competitiva para uma empresa (KNOTT, 2015). A estrutura VRIO consiste em quatro critérios principais sobre um recurso ou capabilidade para determinar seu potencial competitivo:

1. Valor: o recurso / capabilidade permite que a empresa melhore sua eficiência ou eficácia?

2. Raridade: o controle do recurso / capabilidade está nas mãos de poucos?

3. Imitabilidade: é difícil de imitar e haverá desvantagem de custo significativa para uma empresa que tente obter, desenvolver ou duplicar o recurso / capabilidade?

4. Organização: a empresa está organizada de forma a estar pronta e capaz de explorar o recurso / capabilidade?

Barney (1991) categoriza três tipos de recursos:

1. Recursos de capital físico (físico, tecnológico, instalações e equipamentos),

2. Recursos de capital humano (treinamento, experiência, insights) e

3. Recursos de capital organizacional (estrutura formal).

$\mathrm{Na}$ visão baseada em recursos de Barney (1991), os recursos da firma incluem recursos de TI e fatores organizacionais. Nesse sentido, a firma pode ganhar vantagem competitiva baseada nos seus recursos e melhoria no desempenho quando seus recursos são simultaneamente valiosos, raros, imperfeitamente imitáveis e organizacionais. Embora os recursos de TI estão cada vez mais "sozinhos" visto não serem capazes de atender a esses requisitos, os recursos de TI e os fatores organizacionais complementares, quando juntos, podem atender às condições necessárias, criando as capabilidades e se tornando uma fonte sustentável de vantagem competitiva e melhoria de desempenho (CAO ET AL, 2011). 


\subsection{BUSINESS ANALYTICS E A VISÃO BASEADA EM RECURSOS}

Pesquisas sinalizam que as tecnologias envolvidas em BA são vistas como um importante investimento estratégico para muitas empresas e elas estão fazendo grandes investimentos em BA, cuja tendência é de continuidade (DAVENPORT; HARRIS, 2007; DAVENPORT, 2013). Essa visão aponta a tecnologia incorporada em BA como algo exógeno (ORLIKOWSKI, 2009) ou seja, possui uma função determinística e focada em melhoria de desempenho (KOHAVI; ROTHLEDER; SIMOUDIS, 2002; DAVENPORT; HARRIS, 2007; PICCOLI; WATSON, 2008; TRKMAN et al., 2010; KLATT, SCHLAEFKE; MOELLER, 2011; VARSHNEY; MOJSILOVIC, 2011; BRONZO et al., 2013; DAVENPORT, 2013; KHAN, 2013; APPELBAUM et al., 2017; WANG; BYRD, 2017; CHEN; NATH, 2018; AYDINER et al., 2019; ASHRAFI et al., 2019).

Nessa lógica, Davenport e Harris (2007) definem BA como o uso extensivo de dados, das análises estatísticas e quantitativas e dos modelos explicativos e preditivos por meio de uma gestão focada em fatos e dados para a tomada de decisão. Portanto, BA engloba as pessoas, os processos e as tecnologias envolvidas em juntar, analisar e transformar dados para suporte no processo de decisão gerencial (JORDAN; ELLEN, 2009) como também é considerado como um conjunto de métodos e práticas que geram valor por meio de dados para indivíduos, empresas e organizações (KRAUS et al, 2020).

BA tem suas raízes em BI (Business Intelligence) no âmbito dos sistemas de apoio à decisão (SAD). Dedic e Stanier (2016) apontam que Business Intelligence (BI) compreende as estratégias e tecnologias utilizadas pelas empresas para a análise de dados de informações comerciais fornecendo visões históricas, atuais e preditivas das operações comerciais. Desta forma, os aspectos tecnológicos da análise estão enraizados nas capacidades de suporte à decisão fornecidas por BI (HOLSAPPLE; LEE-POST; PAKATH, 2014).

Stubbs (2011) e Saxena e Srinivasan (2013) explicam que BI é um subconjunto de BA, já que BI se concentra em analisar e apresentar informações históricas, ou seja, o que aconteceu (STUBBS, 2011). Já uma análise mais avançada, por sua vez, tenta identificar por que as coisas estão acontecendo, bem como prever o que acontecerá a seguir e qual o curso de ação que é recomendado. Business Analytics, de acordo com Stubbs (2011), engloba todos esses conceitos e acrescenta os requisitos de insights gerados, relevância comercial e medição de valor e desempenho. Mcafee e Brynjolfsson (2012) e Lohr (2012) reforçam que sistemas BA são marcados por seu foco crescente no reconhecimento de padrões e previsão, ao invés de histórico de relatórios

Segundo Evans (2016) BA é comumente visto de três grandes perspectivas: descritiva, preditiva e prescritiva. A análise descritiva é o tipo de análise mais usado nas organizações, pois categorizam, caracterizam, consolidam e classificam os dados para convertê-los em informações úteis para fins de compreensão e análise de desempenho do negócio. Esta visão do autor sobre BA engloba a análise de diagnóstico dentro da perspectiva descritiva, pois no processo de diagnóstico ainda não ocorrem previsões nem prescrições

Evans (2016) aborda que a análise preditiva analisa o desempenho passado em um esforço para prever o futuro através da análise de dados históricos, detectando padrões ou relações nestes dados, e depois extrapolam essas relações para um tempo futuro. Por exemplo, um comerciante pode querer prever a resposta de diferentes segmentos de clientes para uma campanha publicitária, um comerciante de commodities pode querer prever movimentos de curto prazo nos preços das commodities.

Ao tratar da terceira perspectiva, Evans (2016) discute que a análise prescritiva usa da otimização para identificar as melhores alternativas para minimizar ou maximizar algum objetivo. A análise prescritiva é usada em muitas áreas de negócio, incluindo as operações, 
marketing e finanças. Por exemplo, pode-se determinar uma estratégia de preços e publicidade para maximizar a receita, a quantidade ideal de dinheiro para armazenar em caixas eletrônicos, ou uma combinação de investimentos em uma carteira de aposentadoria para gerir o risco.

Relacionando BA com a Visão Baseada em Recursos, entende-se que os tomadores de decisão ao se tornarem competidores analíticos por meio de BA, possuem o intuito de melhorar suas capabilidades, ou seja, sua habilidade de ser capaz (BARNEY, 1991) no processo de decisão. Braganza et al. (2017) argumentam, seguindo uma perspectiva da VBR, que os recursos organizacionais relacionados ao Big data podem ser explorados para obter vantagem competitiva quando atendem aos requisitos de VRIN (valor, raridade, imitabilidade imperfeita e não substituibilidade) (BARNEY, 1991).

Estudos anteriores tendiam a examinar o impacto de analytics sobre o desempenho geral de uma organização (AKTER et al., 2016; AYDINER et al., 2019; CHEN; PRESTON; SWINK, 2015; WAMBA et al., 2017; GUNASEKARAN et al., 2016; GUPTA; GEORGE, 2016; SRINIVASAN; SWINK, 2018). A maioria desses estudos descobriu que as organizações que usam BA por meio da grande quantidade de dados (big data) para tomar decisões complexas são mais competitivas no mercado (CHEN; PRESTON; SWINK, 2015; WAMBA et al., 2017; SRINIVASAN; SWINK, 2018). No entanto, Aydiner et al. (2019), em um de seus estudos recentes, concluiu que o nível de desempenho desejado não pode ser alcançado em organizações que não conseguem responder efetivamente às pressões externas relevantes ou demanda ambiental.

Considerando os pilares propostos por Davenport (2006), para que as empresas se tornem competidoras analíticas são necessários: habilidades analíticas, qualidade da informação, tecnologia analítica, comprometimento da liderança e estratégia analítica, pode-se considerálos, dentro da Visão Baseada em Recursos, como um conjunto de recursos necessários para que uma organização tenha a sua orientação analítica, para que desta forma, possa ter vantagem competitiva e melhorar os seus processos.

\subsection{CONHECENDO A ÁREA DE REVENUE MANAGEMENT}

Segundo Strauss, Klein e Steinhardt (2018), Revenue Management (RM) refere-se à prática de gerenciamento de demanda suportada por TI, por meio de preços ou disponibilidade de produto com base em modelos de demanda, de modo a maximizar lucros ou receita. Ela se originou no setor de companhias aéreas na década de 1970, após a desregulamentação do mercado de companhias aéreas dos EUA.

O RM pode ser delineado a partir de uma prática de precificação mais geral por meio do uso de sistemas de computadores que frequentemente são sofisticados e processam automaticamente as vendas e outros dados para produzir previsões de demanda, que por sua vez são usadas para otimizar as decisões de gerenciamento de demanda. Desde a sua concepção, RM tem sido amplamente adotada em muitas áreas, incluindo transporte (trens, aluguel de carros, balsas, transporte de carga), hospitalidade (hotéis, cassinos), radiodifusão e publicidade, entre outros (STRAUSS; KLEIN; STEINHARDT, 2018).

Como apontam Strauss, Klein e Steinhardt (2018), no setor de transporte aéreo, um produto geralmente é um bilhete com o itinerário desejado, ligado a uma tarifa específica e classe de reserva e que pode vir junto com restrições de reserva, como por exemplo, com restrições de permanência mínima. Cada compartimento, em cada voo ponto-a-ponto (chamado de perna) na rede da companhia aérea, e no dia considerado de serviço, representa um recurso com uma determinada capacidade de assento. Cada produto requer um (voo non-stop) ou vários (stopover) desses recursos. Obviamente, em ambos os exemplos, os recursos são perecíveis e sua provisão vem com altos custos fixos. Do lado da demanda, os clientes podem ter preferências 
diferentes, por exemplo, dependendo do objetivo de sua viagem. Uma distinção comum no setor de companhias aéreas é entre viajantes a negócios e turistas. Quando esses grupos de clientes recebem o mesmo conjunto de produtos pela empresa, eles geralmente fazem escolhas diferentes. Além disso, se o seu produto preferido não estiver disponível, eles podem mostrar um comportamento diferente de substituição, ou seja, mudar para produtos diferentes ou não comprar nada (STRAUSS; KLEIN; STEINHARDT, 2018).

Como apontam Koch et al (2017), todos os parâmetros na área de RM - demanda, capacidade e receita - podem estar sujeitos a um padrão estocástico (estado indeterminado, aleatório) e à incerteza. Fatores ambientais, como eventos inesperados, mudanças no cenário competitivo ou o impacto inesperado de defeitos nos sistemas de gerenciamento de receita podem influenciar os parâmetros. A capacidade (oferta) também pode mudar devido a um mau funcionamento ou atrasos inesperados do equipamento. Até mesmo os preços dos produtos são incertos, pois as companhias aéreas tradicionais desenvolveram estruturas de tarifas muito complexas, levando a um grande número de tarifas na mesma rota. Assim, as tarifas são agrupadas e os produtos usados no gerenciamento de receita são médias sobre várias tarifas individuais. Por conseguinte, os seus preços são incertos, uma vez que dependem do mix real de tarifas.

$\mathrm{Na}$ indústria de viagens, os sistemas de reservas oferecem mecanismos para controlar a disponibilidade. Esses mecanismos são geralmente incorporados na lógica de software do sistema de reservas e, como resultado, pode ser bastante caro e difícil de mudar. Portanto, os mecanismos de controle escolhidos para uma dada implementação são frequentemente ditados pelo sistema de reserva (TALLURE; RYZIN, 2004; GALLEGO; TOPALOGLU, 2019).

\section{PERCURSO METODOLÓGICO}

Como locus da pesquisa, foi escolhida uma companhia aérea aqui denominada de STAR por questões de confidencialidade. Essa empresa usualmente utiliza soluções analíticas no dia a dia para diferentes análises dos processos de Revenue Management (gerenciamento da receita).

O trabalho de coleta de dados por meio de observação não participante foi realizado entre os meses de abril e junho de 2017 pela pesquisadora e baseou-se na observação do dia a dia das práticas da área de RM da companhia aérea pesquisada em São Paulo. Do total de 128 horas de observação, 90 horas ficaram com o setor de yield, que é a área em que o gerenciamento de receita se faz mais presente. Para a área de estratégia foram dedicadas 28 horas e 7 horas para o pricing e 3 para o planejamento. Além da observação, dados foram coletados por meio da visualização de relatórios gerados e de entrevistas. Segundo Liu e Maitlis (2010), a observação não participante envolve a observação de participantes sem participação ativa. Esta opção é usada para entender um fenômeno ao entrar na comunidade ou no sistema social envolvido, mantendo-se separado das atividades observadas.

A escolha do local se deu em função da pesquisadora ter contato com informantes-chave da empresa e por possuir longa experiência (14 anos) em empresas aéreas. Apesar disto, a pesquisadora nunca trabalhou na referida empresa. A sede administrativa da companhia fica na região da Grande São Paulo, local onde foi campo desta pesquisa, pois o setor de Revenue Management se situa nesta localidade.

Nesse âmbito, a presente pesquisa adotou entrevistas em conjunto com a observação não participante. Inicialmente foram realizadas entrevistas exploratórias (sem um roteiro elaborado), que ocorreram nos primeiros dias de observação, para que se pudesse ter uma visão mais geral das práticas. Quivy e Campenhoudt (2008) consideram que as entrevistas exploratórias ajudam na constituição da problemática de investigação, ajudando na ampliação 
e ratificação do problema proposto. Já ao final do período de observação, foram aplicadas as entrevistas semiestruturadas.

A opção pelas entrevistas semiestruturadas deveu-se ao fato de serem amplamente utilizadas em pesquisas qualitativas (EDWARDS; HOLLAND, 2013). Uma entrevista semiestruturada é aberta, sendo flexível a novas ideias que podem ser levantadas durante a entrevista, dependendo das respostas do entrevistado. As entrevistas semiestruturadas tiveram duração média de 30 minutos e foram realizadas na última etapa de visitas com o Gerente da área, um coordenador, três analistas (um sênior, um pleno e um júnior), um analista que é responsável pelo desenvolvimento da solução de BI dentro da área e um gerente da área de planejamento. Cada um dos entrevistados foi escolhido pelo potencial de fornecer um maior detalhamento sobre o RM. As entrevistas foram gravadas através do celular, com exceção da entrevista com o Gerente de Planejamento que foi apenas anotada no bloco de notas.

A coleta de dados documental se deu pela observação dos relatórios que são utilizados na área. Foram observados os relatórios considerados padrão pela empresa: tracker, analyzer, daily bookings, competitiveness, entre outros. A escolha desses relatórios foi dada pela frequência com que os relatórios eram consultados pelos analistas. Na primeira semana de observação, foram registrados quais relatórios estavam sendo consultados de maneira recorrente pelos analistas, e a partir das semanas seguintes era perguntado sobre informações pertinentes aos relatórios identificados, ou seja, o analista abria o relatório e se fazia os respectivos questionamentos. Além dos relatórios padrão, foram visualizados diversos relatórios que são desenvolvidos pelos próprios analistas para as suas próprias análises de mercado. A partir da observação do conteúdo desses relatórios, foram anotadas as suas funcionalidades ao longo do caderno de campo.

A análise dos dados foi direcionada pelo método de análise em espiral de Creswell (2013). Essa análise adota uma noção de "zig zag", onde primeiramente os dados são coletados e analisados ao sair do campo e depois há um retorno para coletar mais dados para mais análises, e assim sucessivamente. Na presente pesquisa isso foi evidenciado, pois a cada semana que havia o retorno para campo, mais informações eram obtidas, portanto, novas análises foram realizadas. A análise em espiral (CRESWELL, 2013) segue uma sequência, conforme figura 1:

Figura 1: Análise em expiral de Creswell (2013)

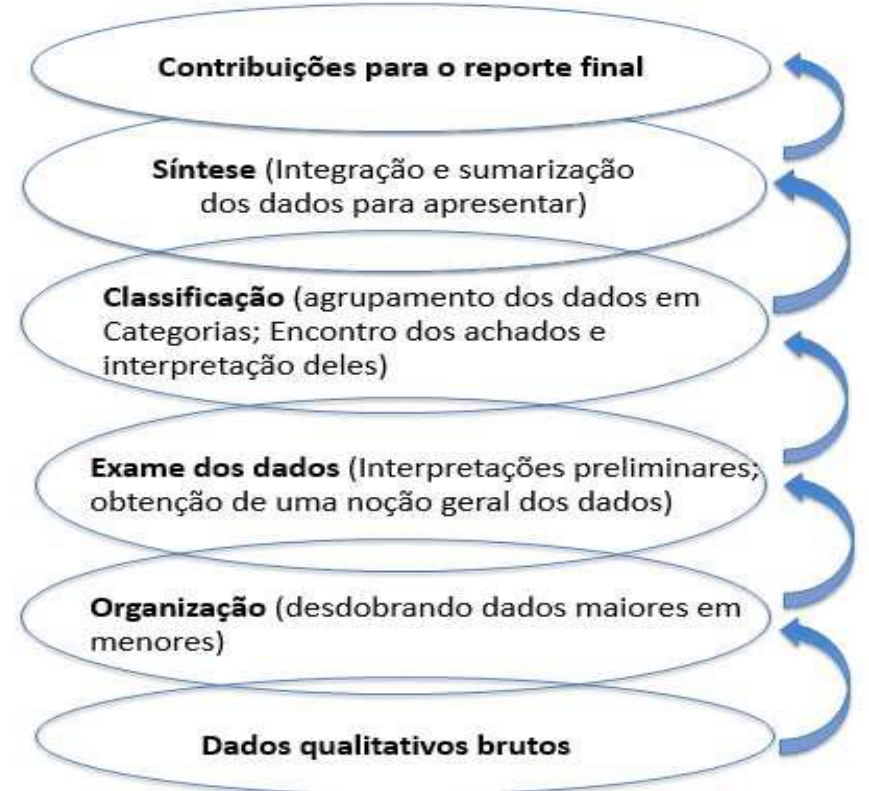

Fonte: Elaborada pela autora e adaptada de Creswell (2013) 
Como já mencionado, o processo de coleta foi por meio de observação com diário de campo, entrevistas e visualização de relatórios (documental). Com todos os dados brutos coletados, foi necessário organizá-los, examiná-los, classificá-los e integrá-los ao final para então oferecer as contribuições necessárias.

Com base nessa concepção, ao fazer um levantamento das ações observadas no setor de RM da empresa aérea pesquisada, houve o entendimento de que as categorias de análise que compõem o gerenciamento de receita são: Otimização de Receita, Análise de Mercado, Geração de relatórios, Desenvolvimento de soluções de BA e Reação à Concorrência. Essas categorias de análise foram definidas por representarem as macroatividades da área de RM detectadas ao longo da coleta de dados (observação e entrevistas).

Para efeito da análise pela Visão Baseada em Recursos, foi utilizado o modelo VRIO de Barney (1995). Dessa forma, após seguir todas os critérios da análise de Creswell (2013), cada categoria foi relacionada a um determinado atributo (VRIO).

Figura 2: Categorias de análise e atributos

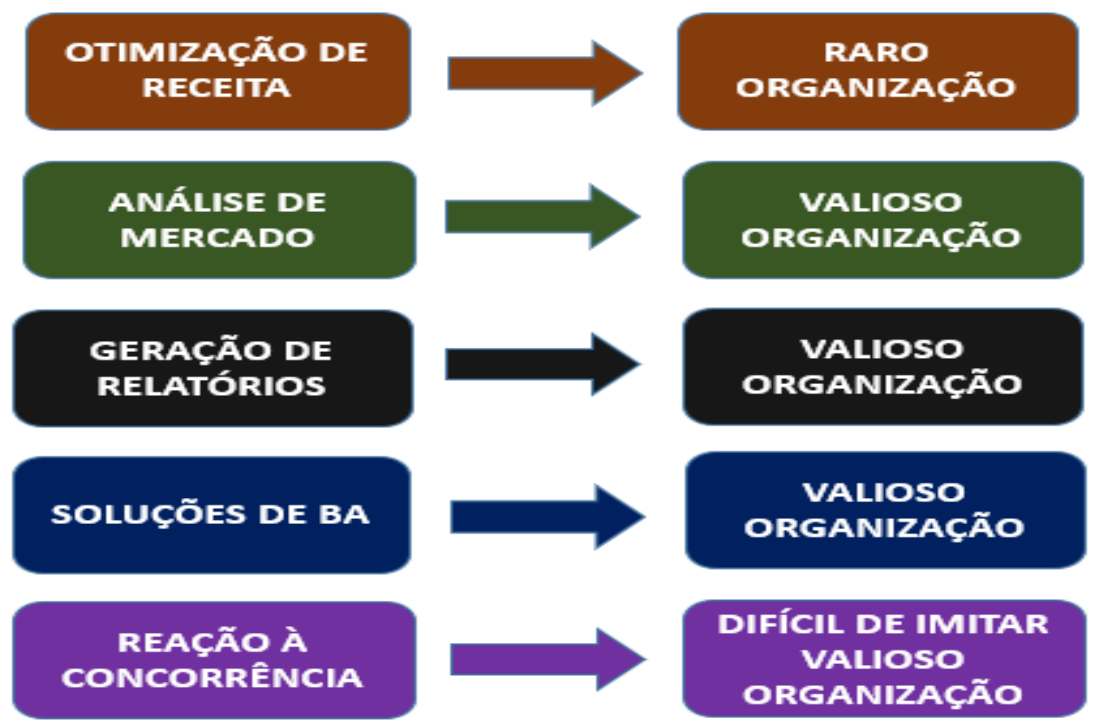

Fonte: Elaborado pela autora (2020)

Conforme observa-se na figura acima, as macroatividades foram examinadas à luz do modelo VRIO e os 4 atributos estiveram presentes, mas não em todas as atividades. $\mathrm{O}$ atributo "Organização" se relacionou com todas as categorias de análise, pois a forma como a empresa se organiza para se tornar competitiva por meio dos seus recursos que podem ser valiosos, raros e de difícil Imitabilidade esteve presente em todas as atividades. O atributo "Valioso" se relacionou com quatro das cinco categorias, só não estando presente na categoria Otimização de Receita. O atributo "Raro" se fez presente em uma categoria (Otimização de Receita) e o atributo "Difícil de imitar" se fez presente na categoria Reação à concorrência. Na sessão de Resultados, cada atividade foi descrita a partir das observações e entrevistas realizadas. A partir destas descrições, buscou-se identificar como os recursos atendem às perguntas norteadoras de cada atributo do VRIO.

O critério para identificação dos atributos foi direcionado pelas perguntas norteadoras de cada atributo do VRIO em confronto com os Recursos Humanos, Físicos e Organizacionais identificados na empresa STAR. A tabela abaixo ilustra o critério utilizado com base em Barney e Hesterly (2007, p.80) 
Tabela 1: Categorias de análise e atributos

\begin{tabular}{|l|l|l|l|l|}
\hline É VALIOSO? & É RARO? & É DIFÍCIL DE IMITAR? & $\begin{array}{l}\text { A EMPRESA ESTÁ } \\
\text { ORGANIZADA PARA } \\
\text { EXPLORAR? }\end{array}$ & QUAL É O RESULTADO? \\
\hline NÃO & & & & Desvantagem competitiva \\
\hline SIM & NÃO & & & Paridade competitiva \\
\hline SIM & SIM & NÃO & & Vantagem competitiva temporária \\
\hline SIM & SIM & SIM & NÃO & Vantagem competitiva que não pode ser utilizada \\
\hline SIM & SIM & SIM & SIM & Vantagem competitiva de longo prazo \\
\hline
\end{tabular}

Fonte: Barney e Hesterly (2007, p.80)

No próximo capítulo, os resultados serão demonstrados e descritos a partir da coleta de dados realizada na empresa STAR.

\section{RESULTADOS}

Ao identificar os recursos organizacionais alinhados com Business Analytics e conectá-los às perguntas norteadoras do modelo VRIO, o seguinte resultado de categoria competitiva foi alcançado conforme a tabela 2 abaixo:

Tabela 2: Recursos analíticos x modelo VRIO

\begin{tabular}{|c|c|c|c|c|c|c|}
\hline & $\begin{array}{l}\text { RECURSO IDENTIFICADO NA } \\
\text { EMPRESA STAR }\end{array}$ & $\begin{array}{l}\text { VALIOSO - o recurso / } \\
\text { capabilidade permite que } \\
\text { a empresa melhore sua } \\
\text { eficiência ou eficácia? }\end{array}$ & $\begin{array}{l}\text { RARO - o controle do } \\
\text { recurso / capabilidade } \\
\text { está nas mãos de poucos? }\end{array}$ & $\begin{array}{l}\text { Não IMITÁVEL - é difícil de imitar } \\
\text { e haverá desvantagem de custo } \\
\text { Significativa para uma empresa } \\
\text { que tente obter, desenvolver ou } \\
\text { duplicar o recurso / capabilidade? }\end{array}$ & $\begin{array}{l}\text { ORGANIZAÇÃO- a empresa } \\
\text { está organizada de forma a } \\
\text { estar pronta e capaz de } \\
\text { explorar o recurso } \\
\text { Capabilidade? }\end{array}$ & $\begin{array}{l}\text { CATEGORIA } \\
\text { COMPETITIVA }\end{array}$ \\
\hline $\begin{array}{l}\text { 1. Recursos de capital físico } \\
\text { (físico, } \\
\text { instalações e equipamentos), }\end{array}$ & $\begin{array}{l}\text { Hardware } \quad \text { (Computadores), } \\
\text { instalaçóes do setor, Tecnologia } \\
\text { de analytics utilizada. }\end{array}$ & SIM & SIM & NÃO & SIM & $\begin{array}{l}\text { VANTAGEM } \\
\text { COMPETITIVA } \\
\text { TEMPORÁRIA }\end{array}$ \\
\hline \begin{tabular}{|l} 
2. Recursos de capital \\
humano (treinamento, \\
experiência, insights) e \\
\end{tabular} & 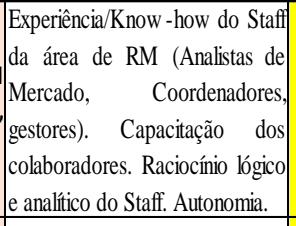 & 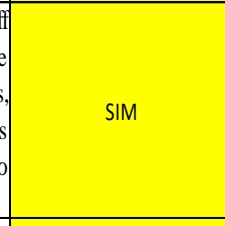 & NÃO & NÃO & SIM & $\begin{array}{l}\text { PARIDADE } \\
\text { COMPETITIVA }\end{array}$ \\
\hline \begin{tabular}{|l} 
3. Recursos de capital \\
organizacional \\
formal).
\end{tabular} & $\begin{array}{l}\text { Gestão da área de RM, Estratégia } \\
\text { voltada para Analytics. Estrutura } \\
\text { dos processos da área, processos } \\
\text { de controle e elaboração de } \\
\text { relatórios, sistema de medição de } \\
\text { desempenho. }\end{array}$ & e & SIM & SIM & SIM & $\begin{array}{l}\text { VANTAGEM } \\
\text { COMPETITIVA DE } \\
\text { LONGO PRAZO }\end{array}$ \\
\hline
\end{tabular}

Fonte: Elaborado pela autora (2021) com base em Barney e Hesterly (2007, p.80)

Conforme descrito na tabela acima, existem diferenças em termos de vantagem competitiva quando analisamos os recursos separadamente. Para melhor identificar como cada recurso é praticado na empresa STAR, cada sub-item desse capítulo tratará de uma categoria, com as devidas conexões ao modelo VRIO de Barney (1995).

\subsection{Análise de Mercado - Valioso e Organização}

A análise de mercado é uma atividade que está relacionada com a análise dos dados da performance da empresa nos seus principais indicadores: Load Factor, que representa o percentual de ocupação dos voos, o RASK, que representa a receita voada por assento $/ \mathrm{km}$, o RPK que representa o $\mathrm{nr}$. de passageiros por $\mathrm{km}$, a tarifa média e o ASK que representa o o 
nr. de assentos por $\mathrm{km}$. Nesta atividade, observa-se que os analistas analisam os indicadores de seus respectivos mercados com um olhar na performance da concorrência.

Há diferentes tipos de análise de mercado e essas análises são realizadas ao olhar o relatório de resultados, ou seja, daquilo que foi voado e do que foi vendido. Há a análise dos mercados considerados críticos (baixa performance) e também há a análise do perfil diário, onde vemos o tipo de mercado, que pode ser considerado competitivo, dominante ou monopólio.

No processo de análise, esses analistas levam em consideração também o preço do ônibus na região em que os mercados são sensíveis a preço, ou seja, que não possuem um índice de ocupação muito bom (abaixo de oitenta por cento). Observou-se que há um foco na competição desses mercados. Como toda a análise, há o acompanhamento das alterações tarifárias e depois se verifica nos gráficos e nos relatórios se essas ações de alteração deram resultado.

Além dos relatórios elaborados pelos próprios analistas, eles têm acesso a uma pasta com relatórios da área do Planejamento, que por sua vez, disponibiliza o Dashboard (painel de controle) nessa pasta, que mostra os mercados, horário de competição, Market share, resultado operacional do voo, ocupação média da empresa e dos competidores, quantidade de frequência de todos os voos e quais são as conexões desse mercado. Dashboard é uma espécie de painel de controle de indicadores, onde são mostrados os resultados desses indicadores. Por se tratar de uma área com muitos relatórios, o que foi possível identificar de forma muito precisa, é que os relatórios têm vida, influenciam e são influenciados pelos analistas de mercado.

As estratégias de mercado acontecem de acordo com o que apontam os indicadores nos relatórios. Se a análise está voltada para um voo muito competitivo, nesse caso o foco dado pelos analistas é na ocupação (load). Já se o mercado for dominante, o foco é a receita (o RASK). O que se percebe é que a empresa busca que os dois indicadores estejam bons e esses resultados são consultados nos relatórios chamados de analyzer e o daily bookings, que são os principais relatórios direcionadores.

Pela fala da entrevistada 4, percebe-se essa forma de análise de otimização:

\begin{abstract}
Nessa otimização eu levo muito em conta aceleração do voo, talvez se está entrando muito ou não nos últimos três dias, eu deixo mais aberto ou fecho, então é mais aceleração do voo mesmo, e da quantidade que eu consigo cobrar mais. Então eu vejo as últimas classes reservadas e aí em cima disso eu vejo se eu fecho mais... se eu consigo fechar .... concorrência também...se eles estão com a tarifa ou não, se bem que dependendo se o voo está muito acelerado eu não levo em consideração a tarifa.
\end{abstract}

Essa otimização, que será melhor relatada no próximo tópico, necessita de uma consistente análise. A empresa adota uma planilha eletrônica programada para fazer essas otimizações em conjunto com os sistemas de reservas e tarifas. Na área sempre ocorre o debate a respeito dos benefícios que o modelo da tracker traz, em detrimento de sistemas de RM, justamente pela flexibilidade que o analista tem em moldar os seus mercados. Apesar da amigável interação, a cobrança dos coordenadores aos analistas é evidente, não só verbalmente e por e-mail, mas também por meio de um relatório específico. Existe um relatório de plano de ação elaborado pela coordenação e que é direcionado a todos os analistas. Ao filtrar o nome do analista, os analistas têm que registrar as ações tomadas com relação às análises realizadas. Isso é uma forma de registro das ações para acompanhamento da Coordenação. Neste relatório há o número de dias em atraso do reporte, o motivo da ação (aumento, redução ou manutenção).

Esses relatos indicam que a forma como a empresa organiza seus processos e os seus recursos humanos e tecnológicos é bem peculiar e sempre objetiva o atingimento dos seus resultados, sendo, portanto, considerada Valioso no modelo VRIO de Barney (1995). 
Foram identificadas diversas interações ao longo do período como, por exemplo, em um episódio em que a Coordenadora dá instruções a uma analista sobre determinado mercado, indicando que há ociosidade e que necessita fazer análise. Essa interação entre a coordenação e os analistas ficou evidenciada na fala de uma das coordenadoras (Entrevistada 6):

Eu valorizo muito trabalhar com as pessoas, embora a gente trabalhe com números e resultado de receita, a cobrança em cima disso é muito grande, mas são as pessoas que trabalham gerenciando esses números. Então assim eu trabalho muito perto, eu gosto de estar muito próxima, próxima dos analistas para analisar, para ajudar, para apoiar nas decisões, mas ao mesmo tempo eu gosto da autonomia, então assim eu acho que depende da fase do nível que os analistas estão, mas eu acho importante estar próxima do analista e do mesmo jeito com os pares e a gestão assim.

Essa fala indica o lado "Valioso" dos recursos humanos do modelo VRIO de Barney (1995). A autonomia dada aos analistas e a interação harmônica existente na área de RM, faz com que a empresa cuide do processo com mais eficiência e atinja seus objetivos de forma eficaz.

\subsection{Otimização de Receita - Raro e Organização}

A otimização de receita na empresa STAR segue um processo muito peculiar, e portanto, Raro, pois enquanto a maioria das empresas utiliza um sistema específico de otimização, a empresa STAR utiliza a Tracker, que é uma planilha desenvolvida pela organização focada em otimização com muitas particularidades.

A tracker é uma planilha que é conectada ao banco de dados da empresa e demonstra o planejamento de ocupação e receita. A planilha tracker possui várias "abas", sendo que cada aba trata de um mercado específico e a ordem das abas segue a prioridade de receita, ou seja, os mercados mais rentáveis são os primeiros. Na hora de fazer a análise, há uma priorização aos mercados de maior receita, depois os mais críticos e por último os de menor receita. A tracker possui categorias que são numeradas e são compostas da seguinte maneira: antecedência de compra menor (pede menos ocupação - normalmente mercado Business que paga mais caro); intermediária; antecedência de compra maior (pede uma ocupação maior pois as tarifas são mais baixas).

Há também uma distinção quanto as estruturas tarifárias (high - horários de pico - ex: segunda-feira pela manhã; sexta à tarde; Low - períodos de menor demanda). A tracker possui colunas que são divididas da seguinte maneira: mercado, data, dia da semana, season, número do voo, horário, categoria, classe, range de datas, reservas não emitidas, load factor, curva de load esperada, tarifa média vendida, quantidade de passagens vendidas no mês, quantidade de passagens vendidas no mês anterior, o histórico de ocupação da tarifa média e a tarifa da concorrência.

Essas informações expostas na tracker são consideradas pelos analistas como suficientes para a tomada de decisão, mas há a complementariedade com outros relatórios como narra a entrevistada 4:

Desde a hora que eu chego na parte da manhã olho os e-mails do dia anterior, aí a gente tem o processo da tracker que é o primeiro passo do dia. Assim que alguém gera a tracker os primeiros passos que vou fazer é otimizar os voos da manhã, então a gente tem todas as carteiras dos voos... a gente faz essa otimização e nesse meio tempo também eu já vou abrindo outros relatórios, daily bookings, analyzer... que nesse período da manhã também que a gente faz as variações de tarifas, a gente vê o que a concorrência fez de alteração e aí é nesse período também que eu vejo o que vou fazer, ou eu vou reduzir, ou eu vou aumentar ou vou seguir, então já tomo as minhas ações no período da manhã. 
Ao mesmo tempo que os analistas fazem a tracker, abrem outras telas, como por exemplo, abrem um canal de compra na outra tela para observar as tarifas da concorrência, ou seja, são realizadas várias consultas a diversos relatórios ao mesmo tempo, em um processo de contínua interatividade. A atividade de executar a tracker evidencia a raridade do recurso na área de RM.

Um exemplo é quando uma analista estava fazendo sua tracker para um período close in (próximos sete dias). Essa disponibilidade para o curto prazo (7 dias) é feita manualmente de acordo com as informações que a própria tracker informa sobre o nível de ocupação. Isso dá uma autonomia ao analista, mas, ao mesmo tempo, percebe-se que esse processo não poderia ser feito sem a sinalização da tracker de como está o mercado, pois como já falado, a tracker é interligada ao banco de dados da empresa, que após ela ser "rodada" para ser atualizada, tem seu caráter prescritivo (EVANS, 2016) de otimização bem presente.

Essa autonomia é relatada pela entrevistada 6 ao ser questionada sobre a interação homem máquina no setor:

Sim ela é eficaz, apesar que tem muito desenvolvimento para ser feito ainda, mas eu acho que essa interação é necessária, apesar que o mais importante é a alimentação que o analista dá para essa ferramenta .

A atualização da tracker com o banco de dados é chamada na área de Joyn. Esse processo de "rodar a Joyn" acontece para a atualização de todos os relatórios, pois há uma interligação com o sistema de reserva (bookings), com o chamado "reference data" que são os parâmetros e com o sistema QL2, que busca nos sites todos os preços da concorrência para oferecer as informações em tempo real.

Há uma pessoa para fazer o joyn três vezes ao dia. Esse processo é revezado (cada dia uma pessoa executa esse processo - uma faz de manhã, outra à tarde e outra no final do dia existe uma escala para isso). Esses analistas acabam expressando alguns termos do cotidiano como, por exemplo, demanda "close in", que demonstra a demanda para os próximos 7 dias e o "further out" que funciona a partir de 14 dias. A multiplicidade de tarefas que os analistas precisam executar são diversas. Observou-se por exemplo, a necessidade de responder e-mails de caráter urgente ao longo do dia.

Um exemplo claro é quando um analista verifica um e-mail recebido com alguns dados (planilha) e interrompe sua tracker para consolidar alguns dados para enviar para outra coordenadora, pois a sua coordenadora encontrava-se em treinamento naquele momento. Isso demonstra um caráter colaborativo entre os analistas e coordenadoras. Esse analista então insere uma coluna com comparativo de ônibus (site de compra) na planilha recebida, coloca a fonte do relatório e envia para a coordenadora, depois disso, o analista volta para a sua tracker.

No que tange aos mercados que são analisados, houve um relato de uma analista, que se considera mais "agressiva" nas suas análises, de que o mercado competitivo muitas vezes "sofre", pois às vezes entram promoções de madrugada da concorrência e a planilha não reflete isso, pois os dados da concorrência entram antes, então se faz necessário realizar ajustes. Eu identifiquei uma preocupação acentuada com os dados da concorrência e isso leva à multiplicidade de tarefas que são realizadas ao mesmo tempo da execução da tracker. Além de interações entre analistas e coordenadoras, os analistas consultam diversos relatórios, sites de compra e e-mails, ao mesmo tempo.

A consulta à curva de demanda do mercado é constante, pois os analistas a consultam para verificarem se as suas ações estão sendo efetivas. Ao mesmo tempo que olham a curva, abrem e-mails e, procuram atendê-los e algumas vezes se levantam para consultar as coordenadoras. A natureza dos e-mails é diversificada, desde relatórios recebidos da área de estratégia e do 
Planejamento, como também solicitações de lugares em voos, status de alguns mercados e outras informações diversas solicitadas pelos gestores.

Um outro momento em que foi identificada a realização de muitas tarefas simultaneamente, foi quando do acompanhamento de uma analista que estava fazendo o seu $6^{\circ}$ mercado na tracker, sendo que, ao todo, ela possuía 12 mercados. A preocupação com o tempo era visível com o agravante de que ela interrompeu sua tracker várias vezes para realizar atividades paralelas necessárias. A analista fazia anotações no seu caderno, entrava no sistema skyspeed para ver a tarifa aplicada pela empresa e voltava para a planilha, em uma sequência bem acelerada.

Ao mesmo tempo, o gerente geral enviou uma solicitação por e-mail e ela teve que parar a tracker para atender a demanda. Ela rapidamente atendeu à solicitação e enviou o solicitado, que era uma planilha que ela havia feito mais cedo, mas o gestor pediu em um formato diferente, portanto, teve que fazer alterações. Após esse momento, ela voltou para a tracker. Essa sequência acelerada de atividades continuou, como mostra uma parte do diário de campo:

\begin{abstract}
Em outra tela, ela enviou uma tarifa para que a Gerente de Pricing criasse no sistema (via tela de mensagem interna). Para isso, ela copiou a tela de um site de compra e colou. Em seguida, ela voltou para a sua tracker. Ela interrompeu novamente a tracker para abrir uma planilha e criar uma tarifa, depois recebeu um e-mail com outra solicitação de lugar no voo, mas respondeu que não conseguiria atender por falta de lugar. Ela checou no skyspeed e verificou se a tarifa que havia pedido alteração ao Pricing foi alterada. Ela respondeu o e-mail dizendo que o voo está lotado e que não pode atender. Ela interagiu com a gerente de Pricing a respeito do comportamento de um concorrente e de qual decisão ela deveria tomar e voltou para finalizar sua tracker.
\end{abstract}

Essa multiplicidade de tarefas e interrupções causa muitas vezes um certo desconforto, como foi retratada na entrevistada 5:

\begin{abstract}
Isso acontece todos os dias e o dia inteiro, a gente programa um schedule e de repente surge uma demanda nova... para-se tudo e não se dá prioridade para o que de fato tem uma prioridade maior do que outras coisas, um exemplo, ontem a gente teve uma apresentação de rotas novas que a gente vai trabalhar então parou-se em umas três ou quatro horas para falar sobre aquilo que vai só acontecer em dezembro.
\end{abstract}

A última tracker é usada para avaliar se as ações da $1^{a}$ tracker surtiram efeito. Foi observado que a primeira tracker leva em média de 1:30 a 2 horas para ser executada, já a última leva em média 40 minutos. A segunda (do horário do almoço) só é feita para alguns casos excepcionais, caso haja uma forte movimentação de demanda. Os analistas vão fazendo simulações na tracker buscando o atingimento do load desejado, isso é uma característica de Business Analytics, ou seja, o seu foco preditivo (EVANS, 2016). A tracker já tem uma programação padrão e possui os mecanismos descritos no Quadro 1:

Quadro 1: Mecanismo de Programação da Tracker

\begin{tabular}{|l|l|}
\hline Programação em dias & $\begin{array}{l}\text { Autonomia do analista versus } \\
\text { automatização }\end{array}$ \\
\hline Voos de 1 a 7 dias (Tracker) & Programação manual pelo analista \\
\hline Voos de 8 a 60 dias (Shape) & $\begin{array}{l}\text { O analista pode mexer na categoria e na } \\
\text { classe, mas a otimização é automática }\end{array}$ \\
\hline Voos acima de 60 dias & $\begin{array}{l}\text { Todo o processo é automático. O analista } \\
\text { não mexe nos campos da Tracker }\end{array}$ \\
\hline
\end{tabular}

Fonte: Elaborado pela autora (2018) 
Há também uma análise descritiva mostrando a tarifa histórica, load histórico, a situação atual do voo (exceptions, status). Então a shape (tracker depois de 7 dias) faz a seguinte análise prescritiva: está abaixo ou acima da curva? Logo, sugere a ocupação que deveria ocorrer com a antecedência determinada e mostra a situação (previsto versus realizado). Um ponto importante observado sobre a tracker/shape, é que existem algumas parametrizações que são feitas para o suporte da tracker, como por exemplo, o relatório time periods com os ajustes das datas (ex: o feriado na segunda não pode ser comparado com um que caia na terça). A entrevistada 2 relata a importância da tracker:

\begin{abstract}
Hoje a gente trabalha com a tracker que foi desenvolvida pela gestão, é uma coisa automática e manual ao mesmo tempo, eu preciso muito dos inputs dos analistas para que ela funcione, existe uma parte automática que ela faz sozinha, mas que alguém gerenciou aquele código, alguém parametrizou aquele código e quando chega na mão do analista é mais manual. Então assim eu vejo isso positivo porque a gente precisa das pessoas eu preciso das pessoas pensando, analisando e não simplesmente o sistema executando, porque a grande diferença de grandes sistemas em companhias áreas é assim, a pessoa gera em si, parametriza aquele sistema para funcionar da maneira que se quer, que precisa que é necessário. E a tracker é um pouco mais flexível o que ajuda a gente a trabalhar de maneira dinâmica que hoje a empresa trabalha.
\end{abstract}

As análises de mercado acontecem simultaneamente à elaboração da tracker, porque para a programação da tracker, são necessárias análises por parte dos analistas e pela própria tracker, que faz a sugestão de acordo com as três atualizações com o banco de dados da empresa. Além do preenchimento da tracker, os analistas fazem suas análises para a shape (voos após sete dias) e para o atendimento de demandas que surgem, como na elaboração de relatórios, verificação de disponibilidade em voos para passageiros individuais e grupos, análises que são solicitadas de determinados mercados, solicitações diversas e análises de novos mercados.

No caso específico da área de RM da empresa pesquisada, pode-se observar pela fala da entrevistada 4 a respeito da tracker e do sistema de reservas Navitaire:

\footnotetext{
A nossa ferramenta é cem por cento útil .... gente precisa tanto da tracker que é o que a gente fica em cima todos dias, porque ela que dá os parâmetros para a gente, então assim...não vejo o sistema Navitaire sem a tracker... eu não consigo enxergar essas duas ferramentas separadas. Totalmente interligadas, então assim a tracker tem uma visão, mas no Navitaire eu consigo ter outra visão dos preços e na tracker a gente consegue ter todo o desenho do inventário, que eu não tenho essa visão no Navitaire e nem em qualquer outro relatório... então as outras ferramentas são complementos da tracker.
}

A realização da tracker é controlada pelas coordenadoras da área. As coordenadoras conseguem visualizar uma pasta chamada review mostrando quais analistas já fizeram a tracker. Também recebem e-mail que vem da estratégia mostrando os kpi's (indicadores de desempenho) por analista, relatórios da área de Pricing mostrando as alterações que a concorrência fez e de tarifas especiais. As coordenadoras também recebem notificações do planejamento a respeito de voos extras para grandes eventos como o Rock in Rio por exemplo, além de outras informações relacionadas à frota e oferta de assentos.

No que tange à demanda, um outro analista narra que recebeu uma informação do planejamento de que as condições andam um pouco "ruins" em determinado mercado e que tem que ter ações para incentivar a demanda. Em virtude dessa condição ruim, houve uma redução na oferta de voos. Tratava-se de um mercado business que é mais forte no período próximo (1 a 7 dias - close in). Para tanto, o analista olha o relatório de competitividade (competitiveness) e vê que o percentual de conexão está rendendo pouco, então decide fechar 
um pouco mais as opções de conexão. Já para voos no shape (após sete dias) a própria planilha já abre ou fecha mais os voos, e isso é feito automaticamente.

Essas sugestões são análises prescritivas (EVANS, 2016) no ambiente de Business Analytics, e são programadas por meio de algoritmos. Nessas múltiplas tarefas especificadas, foi identificada uma preocupação com a análise de demanda, assim como relata uma das coordenadoras: "é preciso passar a focar mais em voos futuros, ou seja, numa análise de demanda". Há de fato uma preocupação quando se tem queda de demanda, pois como a coordenadora relata: "tem que fazer uma boa investigação, e que fazer isso não é fácil".

Existem outras análises que são influenciadas por fatores externos também. Há um software estatístico que projeta as limitações de capacidade (temperatura, peso, quantidade de passageiros) dos aeroportos e que precisa obrigatoriamente ser utilizado no aeroporto Santos Dumont no Rio de Janeiro. Essa situação específica do aeroporto Santos Dumont interfere na rotina do analista, pois ele precisa, por exemplo, olhar no site do Climatempo para ver o tempo no Rio de Janeiro. Ou seja, se estiver muito quente no Rio de Janeiro, isso interfere na oferta de assentos dos voos que saem de lá.

\title{
4.3 Geração de relatórios - Valioso e Organização
}

As interações da área de yield com as áreas de Estratégia, Pricing e Planejamento são rotineiras e na opinião de uma coordenadora de yield, são muitos os relatórios recebidos da área de Estratégia, que por outro lado ajudam muito nas análises de mercado, mas que é preciso filtrar o que vai ser utilizado ou não. Como evidenciado na entrevistada 2 :

Hoje eu acho que os relatórios atendem bastante as nossas necessidades, a nossa rotina, as atividades diárias, é muita informação, então a gente tem até dificuldade quando entra um funcionário novo, para ele conseguir entender para que ele vai usar cada relatório. A gente tem muita coisa, um leque de opções de variedades absurdas e a gente tenta direcionar isso para de fato o que é útil a gente faz até reuniões esporádicas, essa área (estratégia) questiona muito a gente em relação a isso do tipo “existe esse relatório, ele é utilizado ou não? preciso enviá-lo ou ele pode ser só gerencial?

A entrevistada 6 relata esse excesso de informações recebidas também:

\begin{abstract}
Sim eu acho que tem relatórios ali que até vem em excesso, porque é a mesma coisa de outro formato. Os relatórios por exemplo de tarifas que a gente recebe um formato de manhã e dois formatos a tarde, então eu acho que tem coisa que vem até demais, eu acho que o medo de pecar por menos então acaba sobrecarregando.
\end{abstract}

Nesse âmbito de interação com outras áreas e de relatórios recebidos, normalmente a informação de novos mercados é dada pela área de planejamento, e a partir dessa informação os analistas do yield precisam fazer suas análises. Em dado momento, uma analista Júnior estava fazendo a análise de um novo mercado de concorrência e estava conferindo no site o horário e o preço. A analista criou seu próprio relatório em que customizou todos os seus mercados. Nesse relatório ela colocou a frequência da empresa e da concorrência e fez um para cada mercado dentro da região nordeste.

Ao mesmo tempo em que ela estava preenchendo o relatório, ela olhava para a página da concorrência na outra tela. Ela também observou o equipamento utilizado e relatou que costuma haver picos de oferta no mercado da região, pois disse que tinha o domínio no mercado no passado, mas com a entrada da concorrência, teve que fazer ajustes para se adequar ao novo cenário. Ela também analisa o relatório de tarifas que vem do Pricing. Ou seja, a tomada de decisão é baseada na análise de vários relatórios. 
Essas variações na oferta dos voos que vem do planejamento, reflete nos preços praticados, como preconiza a lei de oferta e demanda de Walras. Uma analista relata por exemplo que quando tem uma queda da oferta (redução de frequência semanal ou diário ou um equipamento menor), há o aumento do preço. Já quando há aumento de oferta, ela diz que fica um pouco "no escuro" porque fica sem referência histórica, mas que entende que pode haver competitividade e pode baixar o preço se for caso.

Outro analista relata algo semelhante sobre a informação que vem do planejamento que é direcionado para todos a respeito da redução da oferta de voos e que devido a isto, ele tem que "proteger" esses voos, ou seja, restringir mais os voos (ex: aumentar o preço), mas mesmo assim o analista confirma a informação no site da concorrência. $\mathrm{O}$ analista ressalta que há uma constante vigilância com a concorrência e que todos os avisos relacionados à concorrência, não vêm só do planejamento, mas também dos próprios gestores.

\subsection{Desenvolvimento de soluções de BA - Valioso e Organização}

Um projeto significativo que vem ocorrendo na área de Estratégia é a finalização do desenvolvimento de um sistema de Business Intelligence para o setor. A observação foi realizada com a analista da área (engenheira de software) de estratégia. Ela era nova de empresa (uns três meses apenas) e foi contratada como analista Sênior exclusivamente para implantar um sistema de BI. É uma profissional que interage diretamente com o setor de TI para as diversas demandas de implantação do software.

Ela relatou que considera que o banco de dados Access é muito limitado e lento para a área de RM e que está capacitando e desenvolvendo o SQL (Structured Query Language), que é a linguagem de pesquisa declarativa padrão para banco de dados relacional (base de dados relacional). A analista está desenvolvendo um BI que ela denomina de self service e que está dentro do pacote da Microsoft. Ela justifica dizendo que o Power BI já está disponível e que é muito amigável para uso e que está entre as três ferramentas mais usadas no mundo. Ela enfatiza que está migrando do Access para o SQL e que vai usar o conceito de Analytics.

Como a base de BA são as características descritivas, preditivas e prescritivas (EVANS, 2016), no momento da observação, a analista estava focando na parte histórica para desenvolver o modelo prescritivo, ou seja, quando o software dá a sugestão do que dever ser feito. O modelo descritivo ficará por conta dos vários gráficos que estavam sendo desenvolvidos e que já estavam prontos. Com relação ao modelo preditivo, ela relatou que vai colocar ferramentas de predição somente depois que finalizar o histórico.

Os gráficos exibidos do modelo descritivo são interativos e um deles mostra o comparativo com a concorrência, que é um relatório extremamente importante para as análises de mercado. Um outro relatório apresenta seis gráficos que mostram a receita acumulada, a tarifa média, os segmentos acumulados, as reservas mensais e a ocupação dos voos no dia de hoje. Quando se clica no gráfico, ele vai mostrando a informação por hora, ou seja, a atualização é em tempo real. Os gráficos também têm uma caixa que mostra os dados para visualização.

O Power BI é um serviço voltado para análise de negócios, e, portanto, está dentro do arcabouço teórico de BA (DAVENPORT; HARRIS, 2007). Segundo informações da Microsoft (Acesso em 19 set 2018), o Power BI possui as seguintes funcionalidades:

1) Fornece insights para permitir decisões rápidas e informadas;

2) Transforma dados em visuais impressionantes;

3) Compartilha dados em qualquer dispositivo;

4) Explora e analisa os dados visualmente (locais ou na nuvem) em uma única exibição;

5) Colabora com relatórios interativos e exibe dashboards personalizados que podem ser compartilhados;

6) Dimensiona a organização com governança e segurança internas. 
A analista pontuou sobre a preocupação com a segurança da informação e colocou que todas as pessoas que têm o e-mail da empresa poderão ter acesso, mas cada um terá acesso ao que for disponibilizado. Os dados do Power BI poderão ser visualizados por analista e por mercado. Como relatado pela analista quando entrevistada (Entrevistada 7), esse processo de construção do Power BI é feito coletivamente por meio de interações com os analistas do yield, outros analistas da área de estratégia e obviamente com a própria tecnologia.

Então eu pego bem na parte da manhã para pensar como que eu vou desenhar, desenvolver esse projeto, então eu faço os cálculos eu converso com os analistas pensando num ângulo melhor de negócios para atender as especificações dele e aí na parte da tarde eu faço todos os desenvolvimentos, então eu faço o deslocamento dos dados com a ferramenta de BI, monto um BI para relatório pra conseguir chegar, então no meu relatório eu vejo as possibilidades de aplicar alguma estatística, alguma coisa mais na parte de analytics.

O que se espera é que o Power BI proporcione uma mudança na rotina dos analistas e agilize as atividades conforme relato da entrevistada 5:

\begin{abstract}
Acho que umas das coisas que a gente mais corre o contra ou a favor é contra o tempo, a gente não consegue executar todas as atividades necessárias durante o dia, então se eu perco muito tempo na atualização de um relatório e de repente eu vou ganhar esse tempo, a qualidade de análise e a qualidade das nossas estratégias vai melhorar infinitamente, assim, vai ser muito positivo ter todas essas informações num caminho só, numa consulta só ganhe-se muito tempo com isso e ganhando tempo ganha dinheiro né.
\end{abstract}

Além da questão do tempo, a analista relata sobre a importância da qualidade dos dados. Ela trabalha com as duas telas e fala como é configurada a estrutura da tracker. Ela diz que a metade da tracker é o SQL e a outra metade é Access e que a ideia é migrar cem por cento para o SQL. Ela diz que a empresa faz a tracker no excel devido à questão de segurança, pois se a tracker for migrada para o Power BI e como este depende da internet, se houver qualquer problema, pode impactar no trabalho executado. Ou seja, a proposta é que o Power BI seja utilizado para ajudar na realização das análises, mas a tracker continuará na plataforma excel, justamente pela questão da flexibilidade dada ao analista em função da dinâmica do mercado de RM. A ideia é diminuir a grande quantidade de relatórios paralelos que são elaborados na área para a realização das análises de mercado.

Isso se observa na fala da entrevistada 7, que defende a necessidade de maior a automatização:

Primeiramente agora no começo, a ideia é automatizar muito mais esse processo de todos, eu digo de coordenador, gerente, analista. Até o vice-presidente. Então eu vejo muito os analistas ali o dia todo na tracker tendo que rodar mercado por mercado... não pode nem levantar porque o movimento é grande porque tem muitos mercados para cuidar e aí eles utilizam várias planilhas do Excel, abrem várias planilhas do Excel e você analisa uma, fecha, analisa outra, fecha, analisa outra. A gente vê também que o computador acaba não aguentando e aí demora para carregar e as vezes eu já vi muita gente parada umas duas horas esperando o computador resolver trabalhar. Então a primeira coisa é automatizar todos os relatórios deles para que não gerem na mão e venha automaticamente. Hoje eles analisam muito informações de um a dois dias atrás. Quem acompanha o BI vai ser hoje, na hora que eu entrar já vai estar atualizado ou já tem a informação já na real do dia.

Outros artefatos, como o celular, estão passando a fazer parte do cotidiano dos executivos da empresa. Em um determinado momento a analista olhou o telefone para fazer um teste sobre o envio de informações e visualização dos gráficos no telefone. Ex: Se a receita aumentar em dez por cento, há um aviso por mensagem e e-mail. Ela relatou que fez esse dashboard para que todos os dias de manhã o VP visualize pelo celular ou tablet com dados da receita e tarifa 
média de hoje, ontem, comparando com o ano passado. A analista demonstrou nesse caso uma preocupação com aspectos de conteúdo e de aparência dos gráficos ao mesmo tempo.

Antes do desenvolvimento desses dashboards para celular do Power BI, as informações eram dispostas apenas nas estações de trabalho e laptops, mas não em dispositivos móveis. Isto é uma desvantagem para os gestores que tinham que estar fisicamente em alguma mesa para consultar seus relatórios.

\subsection{Reação à Concorrência - Valioso, Não imitável e Organização}

No que tange ao acompanhamento da concorrência, há relatórios que explicitam o desempenho dela. Em dado momento, um analista ajustou o relatório com o desempenho do último final de semana para identificar a ação de combate com a concorrência. Nesse momento, o direcionamento foi de que para os voos com ocupação baixa, seria dado um desconto maior. Um exemplo dessas ações são as ações de contrafluxo, como por exemplo, as saídas da região nordeste para outras regiões em período de férias (o que normalmente acontece o inverso) e voos do interior de São Paulo para o restante do Brasil. Observou-se que para o mês de julho foram concedidas tarifas atrativas para voos contrafluxo, tanto para conexão como para voos diretos.

Essa preocupação com a concorrência é evidenciada na fala da entrevistada 1 (E1):

Como sempre devo focar na minha concorrência, olhar o que eu tenho de mercado que tenha concorrência..., verifico tarifas, valores, pra ver também como que a gente está competitivo com isso, procuro verificar qual que é a necessidade daquele mercado naquele momento pra ver também em relação a tomada de decisão pra que lado eu tenha prosseguir e acho que seria mais de analisar mais a minha concorrência, o que meu mercado está precisando e como que eu posso conseguir melhor resultado dentro disso.

Como também na fala da Entrevistada 2 (E2):

Primeiramente a gente precisa ficar atento à movimentação da concorrência. Essa é a primeira atividade que a gente se depara no departamento então eu preciso ver o que a concorrência está fazendo no dia para a gente não ficar fora, então a primeira coisa é a movimentação da concorrência e então a gente vai fazer alterações de preços se necessário.

Para elaborar ações para enfrentar a concorrência, há a consulta de relatórios diversos, dentre eles um relatório de reação para mercados muito competitivos. Um outro relatório que os analistas usam com muita frequência é o daily bookings, que mostra o percentual de vendas por classe, por dia (ex: percentual de venda de determinada classe na segunda-feira). Há a possibilidade de realizar o filtro por mercado, pelo dia da venda e pelo voo). Por meio do daily bookings, os analistas fazem a programação para o que os analistas chamam de season, que são períodos em que a demanda é diferenciada, pois com o aumento de demanda, a tarifa de referência é aumentada consequentemente (ex: um evento de Rally em uma cidade do Mato Grosso do Sul). Em um momento de análise dessa season, o analista verificou que a demanda estava alta e enviou mensagem para outros analistas que têm voos em comum para a cidade onde o Rally aconteceria.

Quando se faz a shape para o segundo semestre por exemplo, existem feriados que são as seasons e que precisam ter tratamento diferenciado por caracterizar uma sazonalidade de demanda. Em algumas situações que envolvem conexões, as análises extrapolam para mais de um analista. No relatório daily bookings há a exposição dos horários de maior venda e o que se vendeu de conexão no mercado. Como o relatório mostra as vendas da semana versus semana anterior, a analista viu que a tarifa se manteve praticamente estável, mas caiu muito na venda de segmentos e então, ela pensa nas possibilidades e em determinado momento fez 
ajuste na tarifa para melhorar a performance de determinado mercado. A analista verificou que determinada conexão despencou nas vendas (exemplo: local $\mathrm{X}$ - local $\mathrm{Y}$ - local Z), sendo que o primeiro trecho (local $\mathrm{X}$ - local $\mathrm{Y}$ ) a analista era a responsável e o segundo trecho (local Y local Z) era de responsabilidade de outro analista

Ela pergunta ao analista da região nordeste se ele tomou alguma ação e em seguida ela verifica a malha (pergunta ao planejamento se houve mudança de malha). Ela mostra um relatório que recebe da estratégia que mostra a quantidade de conexões e diz que tem que tomar ação quando algo sair da normalidade neste relatório. Também existe um relatório que vem do planejamento que mostra o desempenho frente a concorrência dos mercados (ANAC Share). É um relatório consolidado do mês anterior e que todas as empresas aéreas brasileiras recebem, mas a área do planejamento trabalha primeiramente os dados e mostra os pontos que chamam atenção. (Exemplo: Se a empresa STAR cresce 1 ponto, a empresa W perde 2 pontos e a empresa $Z$ perde 6 pontos).

São diversos relatórios que norteiam a área para reação à concorrência e a percepção dos analistas ficou bem evidenciada na fala da entrevistada 3 (E3):

\footnotetext{
Depois da tracker a gente vai fazendo as diversas análises.... isso depende muito do que vai surgir na semana, o mercado que está realmente mais precário precisa mesmo de alguma ajuda porque geralmente a gente tem em média 19 mercados cada um... então a gente vai dando prioridade para o que realmente é necessário ver naquele período, naquele momento entre a shape e responder e-mails, analisando outros relatórios que chegam... geralmente a gente recebe milhões de relatórios todos os dias então a gente tira esse período depois do almoço pra verificar melhor esse relatórios e ver se tem alguma coisa fora da curva ali que a gente precisa verificar.
}

Uma analista que se considera mais "agressiva" nas suas análises, dá um exemplo que subiu a tarifa e melhorou a RASK (receita) mas o load (ocupação) caiu, então foi solicitada a aumentar o load. Esse eterno trade off é rotineiro na área, ou seja, se melhora a performance de um indicador, o outro acaba sendo afetado de alguma maneira. Ela estava fazendo sua tracker e ao mesmo tempo visualizava os dois relatórios, em uma tela estava com a tracker e na outra com o daily bookings. O mercado que a analista atua é de monopólio, por essa razão pode ser considerada um pouco mais "agressiva" nas ações para melhorar o desempenho dos indicadores. Nesse caso, o foco que a analista olha é mais a reação do cliente e não da concorrência, exatamente pelo fato de a empresa STAR exercer um certo domínio sobre a rota.

A forma como a empresa se organiza para reagir à concorrência é diferenciada com a rotina de processos bem definida, o que confirma o atributo "O". Considera-se como não imitável em função da alta confidencialidade e complexa estrutura para acompanhar e superar a concorrência. De fato, é custoso para a concorrência imitar essa estrutura que está por trás do combate à concorrência. Por fim, é valiosa por gerar resultados favoráveis à empresa.

\section{DISCUSSÃO DOS RESULTADOS}

Os resultados mostraram que todos os recursos humanos, físicos e de capital organizacional identificados na empresa STAR estiveram presentes em pelo menos 1 atributo do modelo VRIO (BARNEY; HERTERLY, 2007), o que demonstra que todos os atributos estiveram presentes nas categorias analisadas. Os recursos humanos foram representados pela experiência e Know-how do staff da área de RM (analistas de mercado, gestores e coordenadores), a capacitação (treinamento) e o raciocínio lógico e analítico da equipe, sendo este último apontado como uma condição para que uma empresa se torne uma competidora analítica (DAVENPORT; HARRIS, 2007). Esse recursos humanos foram identificados como 
valiosos (V) e organizacionais $(\mathrm{O})$ o que o torna como "Paridade competitiva" (BARNEY; HERTERLY, 2007).

Como o mercado do setor aéreo é considerado um Oligopólio, em que poucas empresas controlam o mercado, o que se observa é que sua mão de obra se torna muito semelhante entre elas. A própria observação identificou que muitos analistas que ali estavam, já foram colaboradores das concorrentes. Por esta razão, não foram considerados como raros e não imitáveis. No entanto, a valiosidade dos recursos humanos se fez presente em todas as categorias de análise, o que demonstra que o capital humano, quando bem aproveitado pela organização (BRAGANZA et al, 2017), pode gerar vantagem competitiva mesmo que essa vantagem seja de igualdade competitiva (BARNEY; HERTERLY, 2007).

Os recursos físicos foram representados por Hardware (Computadores), instalações do setor e a Tecnologia de analytics utilizada (planilha Tracker, sistema de reservas e Power BI). Esses recursos foram considerados como Vantagem competitiva temporária (BARNEY; HERTERLY, 2007), pois estiveram presentes nos atributos Valioso, Raro e Organizacional. Não foi considerado como "Não imitável" pelo fato de que as tecnologias utilizadas e os recursos físicos são muito similares nas outras empresas aéreas. A planilha tracker é considerada como um atributo Raro, pois é uma especificidade da empresa STAR, inclusive a forma de otimizar a receita nela. Foi desenvolvida por um VP da empresa com grande expertise em tecnologias analíticas, mas não podemos considerá-la como "Não imitável”, pois a tecnologia de elaboração de macros é relativamente simples e as empresas concorrentes já possuem sistemas de otimização de receita (STRAUSS; KLEIN; STEINHARDT, 2018).

Os recursos de capital organizacional foram representados pela gestão da área de RM, da estratégia voltada para Analytics, da estrutura dos processos da área, dos processos de controle e elaboração de relatórios e do sistema de medição de desempenho. Esses recursos obtiveram destaque na análise realizada à luz do VRIO pois estiveram presentes em todos os atributos e, portanto, são considerados como Vantagem Competitiva de longo prazo (BARNEY; HERTERLY, 2007). Observou-se que a forma como a empresa se organiza para explorar os seus recursos analíticos está alinhada com as características descritivas, preditivas e prescritivas de Business Analytics (EVANS, 2016), pois todas as atividades que foram consideradas como categorias (otimização de receita, elaboração de relatórios, análise de mercado, reação à concorrência e soluções de BA) são muito particulares, bem estruturadas e com processos bem definidos e executáveis. Como já descritos nos resultados, conclui-se que são, por estas razões, valiosos, difíceis de imitar, raros e organizacionais.

$\mathrm{O}$ fato de a maioria (4 em 5) das categorias de análise ter sido relacionada com o atributo Valioso, se deve ao fato de que dentro dos atributos analisados (VRIO), os recursos eram voltados para geração de valor, sempre em busca de permitir a exploração de oportunidades e I ou a neutralização de ameaças (BARNEY, 1991). O fato de a categoria Otimização de Receita ter sido classificada como Rara, se deve à particularidade da planilha Tracker, pois a maioria das empresas aéreas utilizam sistemas de RM mais robustos e a empresa STAR prefere utilizar o sistema de reserva em conjunto com a planilha Tracker para realizar o seu processo de otimização. Embora a planilha Tracker seja aparentemente vista como um obstáculo pela falta de avanço tecnológico, para a área de RM como um todo, ela possui vantagem percebida (MARKUS; SILVER, 2008), pois a autonomia dada aos analistas fazem com o processo de otimização seja menos "engessado" e mais flexível às mudanças que acontecem a todo o momento no ambiente da concorrência. Essa flexibilidade é apontada para Koch, Gonsch e Steinhardt (2017) como um atributo necessário na área de RM de uma empresa em função do cenário de incerteza do mercado competitivo. 


\section{CONCLUSÕES E CONSIDERAÇÕES FINAIS}

O objetivo central desta pesquisa foi o de compreender Business Analytics como um recurso estratégico no contexto do Gerenciamento de Receita em uma companhia aérea. O presente artigo problematizou, abriu e revelou a participação dos recursos humanos (analistas, coordenadores e gestores), recursos tecnológicos (artefatos tecnológicos como sistemas de reserva e tarifa, planilha tracker, banco de dados, relatórios em geral) e os recursos organizacionais (estratégia, processos, procedimentos, regras, etc). $\mathrm{O}$ artigo revelou como esses recursos se interligam dentro do contexto de gerenciamento de receita de uma Companhia aérea para gerar vantagem competitiva, mesmo que somente os recursos organizacionais estiveram presentes em todos os atributos VRIO. Pode-se afirmar, portanto, que BA é visto como um recurso estratégico na empresa pesquisada e está inserido em sua estratégia.

Com base da investigação da área de gerenciamento de receita de uma companhia aérea, foi possível concentrar os esforços especificamente em como o gerenciamento de receita possui um conjunto de recursos que geram vantagem competitiva e que sem querer tornam as análises de mercado, a rotina de elaboração da tracker e a produção de relatórios diversos como algo "automático", mas evidenciando cada recurso humano e a sua interface com os recursos tecnológicos e organizacionais.

A utilização da Visão Baseada em Recursos como lente teórica na empresa aérea pesquisada permitiu o rastreamento do processo de gerenciamento de receita num contexto específico, em que o desempenho dos recursos humanos, tecnológicos e organizacionais foi identificado em cada uma das características descritivas, preditivas e prescritivas de BA (EVANS, 2016).

Foi possível avançar na abordagem da Visão Baseada em Recursos ao fazer uma articulação teórica entre o campo de Business Analytics (BA), Gerenciamento de Receita (RM) e a própria Visão Baseada em Recursos (VBR). Dentro das categorias de análise encontradas (Análise de Mercado, Otimização de Receita, Reação à concorrência, Desenvolvimento de solução de BI e Geração de relatórios), e considerando cada característica descritiva, preditiva e prescritiva de BA (EVANS, 2016), cada recurso de capital humano (treinamento, experiência, insights), organizacional (estrutura formal) e físico (físico, tecnológico, instalações e equipamentos) foi descrito na rotina da área de Gerenciamento de Receita. Ao descrever essa rotina, foi possível identificar, dentro do modelo VRIO (BARNEY, 1995), como cada atributo (Valioso, Raro, Inimitável e Organizacional) é evidenciado ao buscar a garantia de eficiência e eficácia dos recursos que são utilizados pela organização.

Ao adotar essa abordagem, este artigo oferece, aos interessados em desenvolver estudos futuros sobre o tema, um caminho para compreender como os gestores respondem às pressões externas, a partir de recursos e capabilidades envolvendo analytics. Assim, os gerentes podem desenvolver estratégias adequadas, que podem moldar seus recursos e estratégias de seleção dentro de suas organizações.

Destacando os recursos tangíveis e habilidades humanas, este artigo oferece insights para gestores lidarem com a "Cultura da Análise", o que pode ajudá-los a entender que alavancar Analytics requer não apenas investimento e tempo, mas também as habilidades humanas adequadas para abordar as necessidades dinâmicas do mercado. $\mathrm{O}$ artigo demonstra que é possível praticar analytics em diferentes níveis como defendiam Davenport e Harris (2007) e que é possível a empresa se tornar uma competidora analítica desde que saiba utilizar os seus recursos de forma efetiva para gerar vantagem competitiva .

Ao compreender Business Analytics como recurso estratégico, as potencialidades dos recursos ficaram evidentes quando foram revelados diferentes tipos de interações existentes nos diferentes aspectos de BA com o uso de uma determinada tecnologia na área de gerenciamento de receita. Novas pesquisas revelando novas interações em diferentes 
contextos, com diferentes tecnologias analíticas podem ser abordadas e podem trazer novas potencialidades para o campo de BA, RM e para o enriquecimento do campo da VBR.

Como pôde ser observado nos relatos do diário de campo, apesar de ter sido identificado aspectos de valiosidade, raridade, não imitabilidade e organizacionais, problemas operacionais foram relatados como na multiplicidade de tarefas dos analistas, que muitas vezes perdem tempo precioso com atividades repetitivas e que poderiam ser aproveitadas com análises mais robustas. A aplicação de um sistema avançado de RM estava em estudo na área, embora a particularidade da tracker seja considerada valiosa e rara pela gestão, exatamente por ter uma flexibilidade maior, dado o dinamismo do setor da aviação civil.

No que concerne às limitações da pesquisa, a primeira limitação encontrada diz respeito ao processo de coleta de dados em si. Por se tratar de uma área estratégica, não foi possível um acompanhamento mais efetivo nas áreas de interface direta com o yield, que seriam as áreas de planejamento e pricing em que foram dedicadas apenas algumas horas durante o período no campo. Seria interessante ter ficado mais tempo nessas áreas para entender melhor os bastidores da dinâmica de algumas atividades desenvolvidas na área. Outra limitação da pesquisa diz respeito à tecnologia utilizada na área de RM pesquisada, pois no período de observação, um sistema de BI estava sendo desenvolvido, mas não havia sido implantado ainda. Nesse caso, a pesquisa teria ficado mais enriquecida, caso o software já estivesse em funcionamento na área, pois seria evidenciada esse novo tipo de recurso utilizado dentro do arcabouço de análise do presente artigo.

Um aspecto importante que precisa ser levado em consideração diz respeito aos desdobramentos da pandemia do Covid-19 no setor aéreo, pois o setor foi fortemente atingido pelas restrições na circulação das pessoas em todo o mundo. Ainda não se sabe quais serão os reflexos no fluxo aéreo no período pós-pandemia, em função do crescimento das tecnologias digitais, o que poderá reduzir a necessidade de deslocamento para viagens, especialmente na área de negócios. No entanto, há uma expectativa de crescimento do turismo para lazer, o que indica que as mudanças no comportamento do consumidor precisarão ser avaliadas com novas pesquisas na área de RM. 


\section{REFERÊNCIAS}

AKTER, S., WAMBA, S. F., GUNASEKARAN, A., DUBEY, R.; CHILDE, S. J. How to improve firm performance using big data analytics capability and business strategy alignment? International Journal of Production Economics, 182, 113-131, 2016.

APPELBAUM, D.; KOGAN, A.; VASARHELYI, M.; YAN, Z. Impact of business analytics and enterprise systems on managerial accounting. International Journal of Accounting Information Systems, [S.1.], v. 25, p. 29-44, 2017.

ASHRAFI, A.; RAVASAN, A.; TRKMAN, P., AFSHARI, S. The role of business analytics capabilities in bolstering firms' agility and performance. International Journal of Information Management, [S.1.], v.47, Dec 2018.

AYDINER, A.; TATOGLU, E.; BAYRAKTAR, E.; ZAIM, S.; DELEB, D. Business analytics and firm performance: The mediating role of business process performance. Journal of Business Research, [S.1.], v.96, p. 228-237, 2019.

BARNEY, J. B. Firm resources and sustained competitive advantage. Journal of Management, v. 17, p. 99-120, 1991.

BARNEY, J. B. Looking inside for competitive advantage, The Academy of Management Executive, 9, pp. 49-61, 1995.

BARNEY, Jay.; HESTERLY, W.S. Administração Estratégica e Vantagem Competitiva, São Paulo: Pearson Prentice Hall, 2007.

BOGDAN, R.; BIKLEN, S. Características da investigação qualitativa. In: BOGDAN, R.; BIKLEN, S. Investigação qualitativa em educação: uma introdução à teoria e aos métodos. Porto: Porto Editora, 1994. p.47- 51.

BRAGANZA, A., et al., Resource management in big data initiatives: Processes and dynamic capabilities, Journal of Business Research ,2016

BRONZO, M.; RESENDE, P.T. V. de; OLIVEIRA, M. P. V. de; MCCORMACK, K.; SOUSA, P. R. de; FERREIRA, R. L. Improving performance aligning business analytics with process orientation. International Journal of information management, [S.1.], v. 33, p.300307, 2013.

CHEN, L.; NATH, R. Business analytics maturity of firms: an examination of the relationships between managerial perception of IT, business analytics maturity and success, Information Systems Management, 35:1, 62-77, 2018.

CRESWELL, J. W. Qualitative Inquiry \& Research Design Choosing among Five Approaches. 3rd ed. Thousand Oaks, CA SAGE, 2013.

CROSS, R. Revenue Management: Hard-Core Tactics for Market Domination. New York, NY: Broadway Books, 1997.

DAVENPORT, T. H.; HARRIS, J. G. Competing on analytics: the new science of winning. Boston: Harvard Business School Press, 2007.

DAVENPORT, T.H. Analytics 3.0. Harvard Business Review, [S.1.], 2013. Disponível em: https://hbr.org/2013/12/analytics-30. Acesso em: 14 maio 2018.

EDWARDS, R.; HOLLAND, J. What is qualitative interviewing? [S.1.]: Bloomsbury Academic, 2013. p. 2-3. 
EVANS, J.R. Business Analytics: Methods, Models and Decisions. 2nd ed. [S.1.]: Pearson, 2016.

GALlEGO, G.; TOPALOGLU, H. Revenue Management and Pricing Analytics. International Series in Operations Research \& Management Science, Springer, v. 279, 2019.

GRANT, R.M., The resource-based theory of competitive advantage: implications for strategy formulation , California Management Review 33 (3) pp.114-135, Berkeley, Calif.: University of California, 1991.

GROVER, V., CHIANG, R. H. L., TING-PENG, L., \& DONGSONG, Z. Creating Strategic Business Value from Big Data Analytics: A Research Framework. Journal of management information systems, 35(2), 388-423, 2018.

GUPTA, M. ; GEORGE, J. F. Toward the development of a big data analytics capability, Information \& Management, 53, pp. 1049-1064, 2016.

ISIK, Ö.; JONES, M. C.; SIDOROVA, A. Business intelligence success: The roles of BI capabilities and decision environments. Information and Management, [S.1.], v. 50, n. 1, p. 13-23, 2013.

JORDAN, J.; ELLEN, C. Business need, data and business intelligence. Journal of Digital Asset Management, [S.1.], v.5, p.10-20, 2009.

KAHNEMAN, D. Thinking, Fast and Slow. New York: Farrar, Strauss, Giroux, 2011.

KHAN, R. Business analytics and supply chain performance: an empirical perspective. International Journal of Operations \& Production Management, [S.1.], v.2, n.3, p.43-56, 2013.

KLATT, T.; SCHLAFKE, M.; MOLLER, K. Integrating business analytics into strategic planning for better performance. Journal of business strategy, v. 32, n. 6, p. 30-39, 2011.

KOCH, S.; GOSCH, J.; STEINHARDT, C. Dynamic Programming Decomposition for Choice-Based Revenue Management with Flexible Products. Transportation ScienceVol. 51, No. 4

KOHAVI, R.; ROTHLEDER, N.; SIMOUDIS, E. Emerging trends in Business Analytics. Communications of the ACM, [S.1.], v. 45, p. 45-48, 2002.

KRAUS, M.; FEUERRIEGEL, S.; OZTEKIN, A. Deep learning in business analytics and operations research: Models, applications and managerial implications, European Journal of Operational Research, Volume 281, Issue 3, p. 628-641, 2020.

HOLSAPPLE, C.; LEE-POST, A.; PAKATH, R. A unified foundation for business analytics. Decision Support Systems, [S.1.], v.64, p. 130-141, 2014.

KRISHNAMOORTHI, S; MATHEW, S. K. Business analytics and business value: A comparative case study. Information \& Management, 55(5), 643-666, 2018.

MARKUS, M. L.; SILVER, M. S. A foundation for the study of IT effects: A new look at DeSanctis and Poole's concepts of structural features and spirit. Journal of the Association for Information Systems, [S.1.], v. 9, n.10/11, p. 609-632, 2008.

MILLER, D. The Resource-Based View of the Firm. In: Business and Management, Oxford University Press, 2019. 
PENROSE, E.Theory of the growth of the firm. Oxford: Oxford University Press,3rd. ed, 1995

PICCOLI, G.; WATSON, R. Profit from Customer Data by Identifying Strategic Opportunities and Adopting the "Born Digital" Approach. MIS Quarterly Executive, [S.1.], p. 113-122, 2008.

SLACK, N.; CHAMBERS, S.; JOHNSTON, R. Administração da produção. Tradução de Maria Teresa Corrêa de Oliveira, Fábio Alher. São Paulo: Atlas, 2008. Título original: Operations management.

SRINIVASAN, R.; SWINK, M. An investigation of visibility and flexibility as complements to supply chain analytics: an organizational information processing theory perspective, Production and Operations Management, 27, pp. 1849-1867, 2018.

STRAUSS, A. K.; KLEIN, R.; STEINHARDT, C. A review of choice-based revenue management: Theory and methods. European Journal of Operational Research, Elsevier, v. 271, n.2, p. 375-387, 2018.

STUBBS, E. The value of business analytics: Identifying the path to profitability. Cary, North Carolina: SAS Institute Inc., 2011.

TALLURI, K. T.; RYZIN, G.J. The Theory and Practice of Revenue Management. Berlin, Germany: Springer Science + Business Media, 2004.

TRKMAN. P; MCCORMACK, K.; OLIVEIRA, M.P.V. de; BRONZO, M.L. The impact of business analytics on supply chain performance. Decision Support Systems, [S.1.], v. 49, p.318-327, 2010.

VARSHNEY, K.; MOJSILOVIC, A. Business Analytics based on financial time series. Methodologies for using data to gain insight into business performance and drive business planning. IEEE Signal Processing Magazine, [S.1.], p.83-93, 2011.

WAMBA, S., A. GUNASEKARAN, S. AKTER, S. , REN, S., DUBEY, R., CHILDE, S. J. Big data analytics and firmperformance: effects of dynamic capabilities, Journal of Business Research, 70, pp. 356-365, 2017.

WANG, Y.; BYRD, T. Business analytics-enabled decision-making effectiveness through knowledge absorptive capacity in health care. Journal of Knowledge Management, [S.1.], v.21, Issue 3, p.517-539, 2017.

WATSON, H.J. Business analytics insight: Hype or here to stay? Business Intelligence Journal, [S.1.], v.16, n.1, p. 4-8, 2010.

WERNERFELT, B; A Resource-Based View of the Firm, Strategic Management Journal, V. 5, No. 2. p. 171-180, 1984. 